\section{Contact investigation for tuberculosis: a systematic review and meta-analysis}

\author{
Gregory J. Fox*, Simone E. Barry ${ }^{\#}$, Warwick J. Britton ${ }^{\#, \uparrow}$ and Guy B. Marks, ${ }^{\star+}$
}

ABSTRACT: Investigation of contacts of patients with tuberculosis (TB) is a priority for TB control in high-income countries, and is increasingly being considered in resource-limited settings. This review was commissioned for a World Health Organization Expert Panel to develop global contact investigation guidelines.

We performed a systematic review and meta-analysis of all studies reporting the prevalence of TB and latent TB infection, and the annual incidence of TB among contacts of patients with TB.

After screening 9,555 titles, we included 203 published studies. In 95 studies from low- and middle-income settings, the prevalence of active TB in all contacts was $3.1 \%(95 \% \mathrm{Cl} 2.2-4.4 \%$, $\left.\mathrm{I}^{2}=99.4 \%\right)$, microbiologically proven TB was $1.2 \%\left(95 \% \mathrm{Cl} 0.9-1.8 \%, \mathrm{I}^{2}=95.9 \%\right)$, and latent TB infection was $51.5 \%\left(95 \% \mathrm{Cl} 47.1-55.8 \%, \mathrm{I}^{2}=\mathbf{9 8 . 9} \%\right)$. The prevalence of TB among household contacts was $3.1 \%\left(95 \% \mathrm{Cl} 2.1-4.5 \%, \mathrm{I}^{2}=98.8 \%\right)$ and among contacts of patients with multidrugresistant or extensively drug-resistant TB was $3.4 \%\left(95 \% \mathrm{Cl} 0.8-12.6 \%, \mathrm{I}^{2}=95.7 \%\right)$. Incidence was greatest in the first year after exposure. In 108 studies from high-income settings, the prevalence of TB among contacts was $1.4 \%\left(95 \% \mathrm{Cl} 1.1-1.8 \%, \mathrm{I}^{2}=98.7 \%\right)$, and the prevalence of latent infection was $28.1 \%\left(95 \% \mathrm{Cl} 24.2-32.4 \%, \mathrm{I}^{2}=99.5 \%\right)$. There was substantial heterogeneity among published studies.

Contacts of TB patients are a high-risk group for developing TB, particularly within the first year. Children $<\mathbf{5}$ yrs of age and people living with HIV are particularly at risk. Policy recommendations must consider evidence of the cost-effectiveness of various contact tracing strategies, and also incorporate complementary strategies to enhance case finding.

KEYWORDS: Contact tracing, early diagnosis, human, Mycobacterium tuberculosis, systematic review, tuberculosis

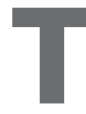
uberculosis (TB) remains a major global health challenge, affecting 8.8 million people each year, most of whom live in low- and middle-income countries [1]. The importance of TB control in social and economic development has been widely acknowledged, including in the Millennium Development Goals. In this context, the World Health Organization (WHO) STOP TB Partnership has set two targets: 1) to reduce prevalence and deaths by $50 \%$ by 2015, relative to 1990 levels; and 2) to eliminate $\mathrm{TB}$ as a public health problem by 2050 [2]. In order to achieve these targets, healthcare systems will need to identify more cases of TB at an earlier stage of the illness [3].

Contact investigation involves the systematic evaluation of the contacts of known TB patients to identify active disease or latent $\mathrm{TB}$ infection (LTBI). It is one of a number of active case-finding strategies that have been proposed to increase case detection [4]. Active case finding may be worthwhile in contacts of patients with TB because they are at higher risk of exposure to the causative organism than members of the general population [5]. After exposure to airborne droplets containing Mycobacterium tuberculosis, some contacts will be infected and some of these will go on to develop disease. The risk of a contact becoming infected relates to the infectiousness of the TB patient, the duration and proximity of the contact [6,7], and susceptibility of the contact $[8,9]$. The onset of disease may occur early, within 6 weeks, or many years later [10]. Contact investigations are undertaken to prevent or detect these cases.

Contact investigation has been standard practice for decades in high-income countries, where the incidence of TB in the general population is low [11]. It may involve clinical assessment, chest
AFFILIATIONS

*Woolcock Institute of Medical Research, University of Sydney, ${ }^{*}$ Centenary Institute of Cancer Medicine and Cell Biology, University of Sydney,

'Discipline of Medicine, Sydney

Medical School, University of

Sydney, and

'Dept of Respiratory Medicine,

Liverpool Hospital, Sydney, Australia.

CORRESPONDENCE

G.J. Fox

Woolcock Institute of Medical

Research

University of Sydney

431 Glebe Point Road

Glebe

Sydney 2037

Australia

E-mail: greg.fox@sydney.edu.au

Received:

May 032012

Accepted after revision:

Aug 102012

First published online:

Aug 302012

The online version of this article has been amended.

The amendment is outlined in the correction published in the August 2015 issue of the European Respiratory Journal [DOI: 10.1183/13993003.50708-2012]. 
radiography, microbiological evaluation of sputum or a test to detect LTBI, such as a tuberculin skin test (TST) or an interferon- $\gamma$ release assay. There has been a growing interest in contact investigation in resource-limited settings as national programmes seek new methods for improving case detection [12]. The WHO currently recommends contact investigation in two high-risk populations: children aged $<5$ yrs [13] and people living with, or at high risk of, HIV infection [14]. Recently, the WHO has also launched the first international standards for the investigation of contacts of patients with infectious TB [15].

One previous meta-analysis examined data from 41 household contact investigation studies in low-middle-income countries up to 2005 [16]. However, there has not yet been an analysis of contact investigation beyond the household setting or in highincome countries. Furthermore, the previous meta-analysis was limited to cases of TB that were diagnosed at the time of the initial contact investigation. There has not yet been a metaanalysis of data on the incidence of TB among contacts during the 5 yrs following exposure. Nor has there been an analysis of key risk groups, such as contacts of patients with multidrugresistant (MDR)-TB. Therefore, the aim of the analysis presented here is to systematically review and quantify data on the prevalence of TB and LTBI and the subsequent incidence of TB in contacts of patients with TB in household and non-household settings in high-, middle- and low-income countries and in various risk groups.

This systematic review and meta-analysis was conducted as a part of a GRADE (Grading of Recommendations Assessment, Development and Evaluation) [17] review for an Expert Panel that was convened to contribute to the development of international guidelines on contact investigation for the WHO [15].

\section{METHODS}

\section{Search strategy and study selection}

This review followed the methods described in the PRISMA statement for the reporting of systematic reviews and metaanalyses [18]. First, we searched the literature for available systematic reviews and meta-analyses, identifying a Cochrane review [19], a systematic review of household contact investigation [16], and two reviews focusing on specific populations [20, 21]. We then designed a search for all published studies that provided a measure of prevalence or incidence of TB or LTBI among contacts of patients with new or recurrent TB. We conducted the search using PubMed, EMBASE, LILACS and Web of Science for all studies up to October 1, 2011. Our search included the terms: "tuberculosis", "Mycobacterium tuberculosis", "tuberculosis, pulmonary", and "contact tracing", " disease outbreaks", "contact", "spread", "contact screen",, "disease transmission", "case find", "cluster analysis", "household", "household contact", "case finding" or "case detection". The full search strategy is available in the supplementary material.

All titles and abstracts were assessed for inclusion according to the following agreed criteria. We included all English language studies that reported a quantitative measure of the TB or LTBI diagnosed among contacts of patients with TB. We only included studies where the number of cases tested was also reported, and where specific source patients with TB (index patients) had been identified before screening was conducted. We excluded studies where the diagnosis of TB was not made according to clinical, radiological or microbiological criteria or where there were less than 10 index patients or contacts identified in the study.

Cross-sectional, case-control studies and cohort studies were included. We also sought evidence from any published randomised controlled trials. We excluded editorials, conference abstracts and systematic reviews.

\section{Data extraction and definitions}

Two reviewers (G.J. Fox and C. Dobler (Woolcock Institute of Medical Research, University of Sydney, Sydney, Australia)) independently screened all titles identified in the database searches. The full-text of all articles included by either reviewer on the basis of abstract was obtained. To determine eligibility for inclusion, one author reviewed all full-text articles. A second author (W.J. Britton) repeated this assessment independently for a random selection of $10 \%$ of full-text articles and there was complete agreement about excluded articles.

Two authors independently extracted data from all of the included studies. One author (G.J. Fox) extracted all data from all studies, and the other authors (S.E. Barry, W.J. Britton and G.B. Marks) independently re-extracted data for six key data fields from all of the included studies between them. Disagreements were resolved by consensus.

Where data from the same contact cohort were included in multiple papers, we included the study with the most complete data. If the reviewers were certain the two studies had the same participants and there were different sets of data in two papers then the results were merged into one entry. If a paper described outcomes in two countries, the data from each were reported separately.

Data extracted from selected studies included: 1) study design, country, location of exposure, selection criteria for index patients and contacts; 2) screening methods employed; and 3) outcomes including number of contacts screened, the number of cases of TB and microbiologically proven disease among contacts, the number of contacts with LTBI, and the number of incident cases each year during the first 5 yrs. Subgroup data were extracted for outcomes of TB, microbiologically proven TB and LTBI among contacts of acid-fast bacilli (AFB) smear-positive and AFB smear-negative source patients (index patients), index patients with HIV, and MDRor extensively drug-resistant (XDR)-TB. Subgroup data were also extracted for contacts that were known to be HIV positive, household contacts, close contacts, casual contacts and contacts from congregate settings.

We analysed data on TB and LTBI for the following age groups: $\leqslant 5$ yrs, $5-14$ yrs and $\geqslant 15$ yrs. Where the limits of the age range reported in studies were up to $1 \mathrm{yr}$ higher or lower than our pre-defined age range, data were included in the predefined range for analysis. Otherwise, the age-specific data were not extracted. Where children were identified as "index patients", then data were included for all screened "contacts" even if an undiagnosed adult might have been the source case.

Household contacts were those living in the same household as the index patient. Contacts were defined as "close" if they 


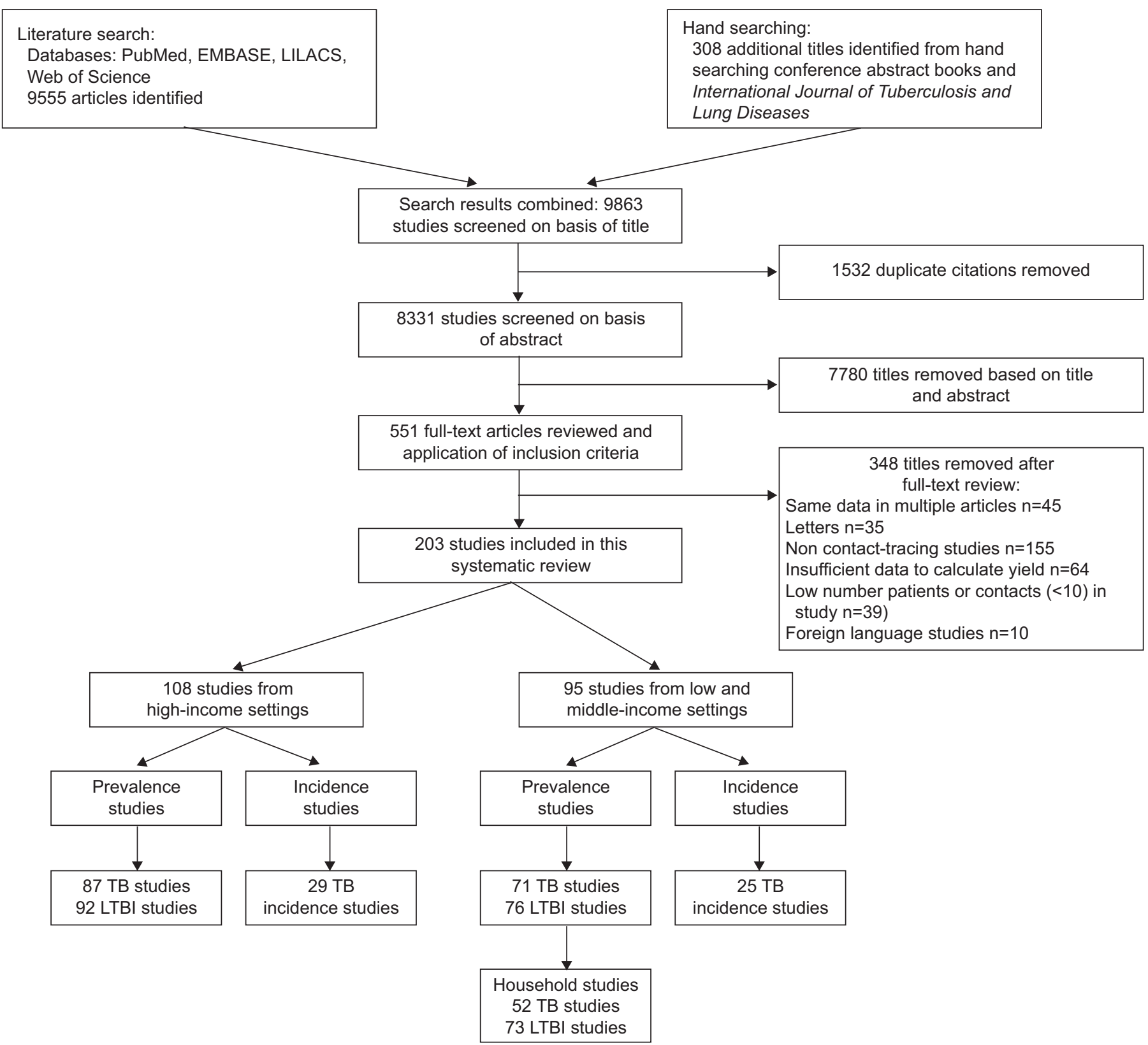

FIGURE 1. Flow diagram for study selection. TB: tuberculosis; LTBI: latent tuberculosis infection.

were described as this in the manuscript, or if they were household contacts.

Prevalent cases of TB among the screened contacts were defined as previously undiagnosed cases of TB among contacts diagnosed during the baseline contact investigation or within the first 3 months after diagnosis of the index patient. Contacts that had been diagnosed with TB prior to the contact investigation were not considered prevalent cases because the identification of these cases could not be attributed to the contact investigation. Incident cases of TB were separately analysed by year after exposure to the index patient with incidence in the first year being from 312 months after diagnosis of the index case, incidence in the second year being between 13 and 24 months, and so on up to the end of 5 yrs. Incidence data were not reported if annual incidence could not be determined. Incidence at $1 \mathrm{yr}$ was calculated excluding the prevalent cases identified during the initial investigation. Contacts were included in the "at risk" population for analysis if they attended the first reported screening procedure and had not already been diagnosed with TB prior to that screening procedure. This at risk population was the denominator for the estimation of prevalence and subsequent incidence.

We defined LTBI as having a TST $\geqslant 10 \mathrm{~mm}$ at $48-72 \mathrm{~h}$. Where these data were not available we used the definition applied in the paper.

Studies were stratified by income level of the country in which they were conducted by applying the World Bank definitions of high-income or low-middle-income countries based on gross national income from 2010 or the latest preceding year 
TABLE 1 Prevalence of active tuberculosis (TB) among contacts in low-middle- and high-income countries

$\begin{array}{ccccccc}\begin{array}{c}\text { Included } \\ \text { studies }\end{array} & \begin{array}{c}\text { Contacts with } \\ \text { active TB }\end{array} & \begin{array}{c}\text { Contacts } \\ \text { screened }\end{array} & \text { Proportion } \% & 95 \% \mathrm{Cl} & \tau^{2} & 1^{2}\end{array}$

\begin{tabular}{|c|c|c|c|c|c|c|c|}
\hline \multicolumn{8}{|l|}{ Low-middle income } \\
\hline $\mathrm{All}^{\#}$ & 71 & 24799 & 878724 & 3.1 & $2.2-4.4$ & 2.18 & 99.4 \\
\hline Index patient smear positive & 44 & 1415 & 43960 & 3.3 & $2.2-5.1$ & 2.04 & 98.5 \\
\hline Index patient XDR/MDR-TB & 6 & 149 & 5584 & 3.4 & $0.8-12.6$ & 2.88 & 95.7 \\
\hline Household contacts & 68 & 22390 & 858422 & 3.1 & $2.1-4.5$ & 2.35 & 98.8 \\
\hline All close contacts & 70 & 22458 & 860638 & 3.1 & $2.2-4.4$ & 2.22 & 98.8 \\
\hline$\leqslant 5 \mathrm{yrs}$ & 21 & 754 & 5112 & 10.0 & $5.0-18.9$ & 2.35 & 97.8 \\
\hline $5-14$ yrs & 9 & 155 & 1643 & 8.4 & $2.8-22.6$ & 2.51 & 92.5 \\
\hline$\geqslant 15 \mathrm{yrs}$ & 11 & 127 & 3614 & 3.2 & $2.0-5.3$ & 0.53 & 87.1 \\
\hline \multicolumn{8}{|l|}{ High income } \\
\hline \multicolumn{8}{|l|}{ All ages } \\
\hline All ${ }^{\circ}$ & 87 & 5058 & 308048 & 1.4 & $1.1-1.8$ & 1.48 & 98.7 \\
\hline All close contacts & 45 & 3053 & 127699 & 1.9 & $1.3-2.7$ & 1.42 & 98.7 \\
\hline Casual contacts only & 9 & 73 & 15607 & 0.4 & $0.2-0.6$ & 0.30 & 79.9 \\
\hline Contacts with HIV infection & 2 & 15 & 133 & 11.4 & $7.0-18.0$ & 0.00 & 9.0 \\
\hline$\leqslant 5 \mathrm{yrs}$ & 10 & 212 & 4057 & 4.7 & $3.4-6.4$ & 0.18 & 79.0 \\
\hline $5-14$ yrs & 9 & 253 & 5665 & 2.9 & $1.7-5.1$ & 0.56 & 95.5 \\
\hline$\geqslant 15 \mathrm{yrs}$ & 9 & 507 & 17867 & 2.3 & $1.1-4.8$ & 1.19 & 99.0 \\
\hline
\end{tabular}

Data are presented as n, unless otherwise stated. XDR: extensively drug resistant; MDR: multidrug resistant. Countries were classified according to World Bank Income Gross National Income per capita: low income ( $\leqslant \$ 1,005$ per yr); lower-middle income $(\$ 1,006$ to $\$ 3,975$ per yr); upper-middle income $(\$ 3,976$ to $\$ 12,275$ per yr); high income ( $\geqslant \$ 12,276$ per yr) [22]. ${ }^{\#}:[9,32-101] ;{ }^{\uparrow}:[10,30,31,102-184]$. Refer to supplementary material for outcomes of individual included studies.

for which data were available [22]. Studies were also stratified by WHO region. We stratified outcomes according to proximity of exposure (household, close and casual), age group, HIV status of the index patient, HIV status of the contact, smear positivity of the index patient and a diagnosis of MDR-TB in the index patient. We stratified outcomes according to whether contacts and index patients participating in contact investigation were foreigners or born locally. We planned to assess the risk of bias of studies at the level of outcome level. We also planned to determine whether study design was independently associated with yield and, if so, to conduct separate analyses for cross-sectional and cohort studies. More detailed definitions of the diagnostic and stratification criteria are included in the supplementary material.

\section{Summary measures and methods of analysis}

For each study, incidence rate was calculated as the number of incident cases per year divided by the population at risk and prevalence was calculated as the number of prevalent cases expressed as a proportion of the size of the at-risk population. Asymptotic $95 \%$ confidence intervals were calculated using the method of FLEISS [23].

For the meta-analysis weighted average estimates of incidence rate and prevalence were calculated using the exact binomial method of HAMZA et al. [24] fitted using Proc NLMIXED in SAS 9.2 (SAS Institute Inc., Cary, NC, USA).

The effect of study design and country income level (lowmiddle or high) on the estimates was tested using logistic regression fitted by generalised estimating equations with an unstructured covariance matrix in Proc Genmod. Since local and foreign born contacts were assessed and reported in the same study, we used a matched pair analysis to estimate the odds ratios for LTBI and TB among foreign-born contacts compared to local-born contacts. This was performed using Proc Logistic with strata statement.

Incidence rate ratio was calculated for each study that reported incidence in the first year as the ratio of the TB incidence rate during the first year of follow-up, divided by the estimated general population incidence of TB in the mid-year of the study period or in 1990, whichever was the later [25]. For all studies, and for studies classified by income group and by study design, the median and interquartile range for the incidence rate ratio was estimated for the first and second years.

We estimated between study inconsistency as $\mathrm{I}^{2}$, representing the percentage of total variation across studies that was attributable to heterogeneity, using the method proposed by HigGins et al. [26] and RiLEY et al. [27]. Values of $\mathrm{I}^{2}$ near $0 \%$ 


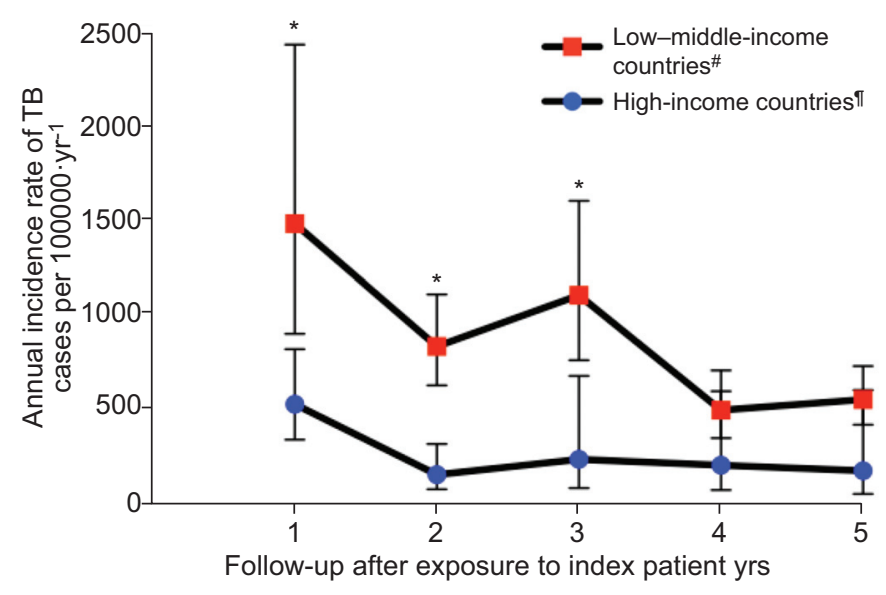

FIGURE 2. Annual incidence rate of tuberculosis (TB) in contacts by year of follow-up, according to country income. World Bank Income Gross National Income per capita: low income ( $\leqslant \$ 1,005$ per yr); lower-middle income ( $\$ 1,006$ to $\$ 3,975$ per yr); upper-middle income $(\$ 3,976$ to $\$ 12,275$ per yr); high income ( $\geqslant \$ 12,276$ per yr) [22]. *: $p<0.05$, statistically significant difference between contacts from high compared to low-middle-income countries. * : [25, 32, 36-50, 102-106, 110127, 185-193]; ': [33, 34, 103-105, 129, 135, 136, 140, 143, 144, 148-151, 153 , $157,163,164,172,194-202]$. Refer to the supplementary material for complete details of outcomes, estimates of heterogeneity and outcomes of individual included studies.

indicates no observed heterogeneity and larger values show increasing heterogeneity. This measure does not inherently depend upon the number of studies in the meta-analysis and can be applied to all study designs [26]. Portions of the code used for the analysis are included in the supplementary material.

\section{Role of the funding source}

No funding bodies had any role in the study design, data collection, data analysis, data interpretation or writing of the report. The authors had access to all study data and are responsible for the decision to submit for publication.

\section{RESULTS}

\section{Study selection and study characteristics}

We identified 9,555 unique publications, and included 108 $(53.2 \%)$ studies performed in high-income countries and 95 $(46.8 \%)$ studies performed in low- and middle-income countries. These 203 studies included 158 studies reporting data on TB disease status of 1,186,772 contacts and 168 studies reporting LTBI status on 345,062 contacts. We included 15 cross-sectional studies, two case-control studies, 185 cohort studies and one randomised controlled trial in the analysis. The reasons for exclusion at each stage are summarised in figure 1. There were an average of 3.8 (95\% CI 2.3-5.0) contacts per index patient in studies from low-middle-income countries and an average of 5.1 (95\% CI 3.1-10.4) contacts per index patients in studies from high-income countries.

\section{Definitions used in studies}

The definitions of "household contact" varied considerably between studies. Some described household based on location, such as a common eating or sleeping area, while some studies stipulated a minimum duration of exposure or degree of proximity [28]. Definitions of close contact also varied considerably in the requisite intensity of exposure to patients. Some studies had a broad definition, with close including any known exposure [29], others used expressions such as intimate [30], sharing the air for a prolonged period [31], or specifying a minimum duration of exposure in other closed spaces such as the workplace [32]. Some studies did not provide precise definitions of close contacts [33].

\section{Low and middle-income countries}

Table 1 shows the summary estimates for prevalence of previously undiagnosed TB. Figure 2 shows the incidence of TB for the first 5 yrs after exposure to the index patient. Table 2 shows the prevalence of LTBI in contacts and table 3 shows the prevalence of microbiologically proven TB. The findings of the individual studies that form the basis of these summary estimates are shown in the supplementary material. There was substantial heterogeneity between studies, indicated by high $\mathrm{I}^{2}$ statistics. TST was used as the primary measure of LTBI in all but six studies, where only Heaf test results were available [34, 102-104].

The estimated overall prevalence of TB (clinically and/or microbiologically diagnosed) in all contacts in low- and middle-income countries was 3.1\% (95\% CI 2.2-4.4, $\mathrm{I}^{2}=99.4 \%$ ). In these countries, the prevalence of TB in household contacts was $3.1 \%$ (95\% CI $\left.2.1-4.5, \mathrm{I}^{2}=98.8 \%\right)$. Prevalence according to setting of exposure is shown in figures 3 and 4 . The prevalence of LTBI among contacts is shown in table 2, and prevalence of microbiologically proven TB is shown in table 3 . The incidence rates for TB up to $5 \mathrm{yrs}$ after exposure are shown in figure 2, with additional incidence data included the supplementary material.

Among contacts of smear-positive index patients the prevalence of TB was 3.3\% (95\% CI 2.2-5.1, $\left.\mathrm{I}^{2}=98.5 \%\right)$ and the prevalence of LTBI was $52.9 \%$ (95\% CI 48.9-56.8, $\left.\mathrm{I}^{2}=97.7 \%\right)$. Among contacts of MDR- or XDR-TB, the prevalence of TB was $3.4 \%\left(95 \%\right.$ CI $\left.0.8-12.6, \mathrm{I}^{2}=95.7 \%\right)$ and the prevalence of LTBI was $61.3 \%$ (95\% CI 39.1-79.6, $\left.\mathrm{I}^{2}=95.2 \%\right)$. Only one study, from Peru, compared the effect of exposure to XDR-TB to MDR-TB and found that the odds of TB among contacts of patients with XDR-TB was 1.88-fold higher than the odds of TB among contacts exposed to MDR-TB (95\% CI 1.1-3.21) [35]. Among contacts of index patients with known HIV, the prevalence of TB was 5.4\% (95\% CI 2.2-12.4, $\left.\mathrm{I}^{2}=95.5 \%\right)$ and prevalence of LTBI was $45.7 \%$ (95\% CI 38.7-52.9, $\mathrm{I}^{2}=90.9 \%$ ).

The prevalence of TB and LTBI among sub-groups including child contacts, close contacts, household contacts and casual contacts are shown in tables 1-3. Outcomes for individual studies are included in the supplementary material.

\section{High-income countries}

The reported prevalence of previously undiagnosed active TB among all contacts from high-income countries was 1.4\% (95\% CI $1.1-1.8, I^{2}=98.7 \%$ ) (table 1 ). The prevalence of disease in household contacts was 3.0\% (95\% CI 2.0-4.4, $\left.\mathrm{I}^{2}=98.2 \%\right)$. The prevalence of LTBI among contacts is shown in table 2. The prevalence of microbiologically proven disease is shown in table 3. Incidence rates of TB among contacts are shown in 
figure 2, with additional details in the supplementary material. For the 11 studies from high-income countries that reported the country of origin of screened subjects, an average of $36.2 \%$ of screened contacts were born overseas. Table 4 shows the weighted prevalence of LTBI was significantly higher among contacts born overseas compared to those born locally (OR 3.39, 95\% CI 3.10-3.71, p<0.0001). Similarly, contacts of foreign born index patients were more likely to be infected than contacts of locally born index patients (OR 2.27, 95\% CI 2.08-2.38, p<0.0001) (refer to supplementary material). There were insufficient data to validly estimate the odds ratio for TB disease.

Among contacts of smear-positive patients in high-income settings, the prevalence of TB was 3.3\% (95\% CI 2.2-4.8, $\left.\mathrm{I}^{2}=98.3 \%\right)$ and the prevalence of LTBI was $34.8 \%(95 \% \mathrm{CI}$ $\left.27.6-42.7, \mathrm{I}^{2}=99.1 \%\right)$. Tables $1-3$ provide data for contact subgroups including contacts of patients with MDR- or XDR-TB, contacts of patients living with HIV, child contacts and contacts with known HIV infection. Outcomes for individual studies are included in the supplementary material.

The median incidence rate ratio (IRR) among contacts during the first year in 29 studies from high-income countries (ratio
46.6, interquartile range (IQR) 3.2-68.0) was substantially higher than that for 25 studies in low-middle-income countries (ratio 15.9, IQR 2.6-21.4). During the second year after exposure, the median IRR for contacts was 9.7 (IQR 2.3-28.6) for 18 high-income and 6.0 (IQR 1.8-105) for 19 low-middleincome countries.

\section{Congregate settings and casual contacts}

We identified no studies of contact investigation from lowmiddle-income countries in congregate settings or among only casual contacts. Table 5 summarises the outcomes of the contact investigation for published studies from congregate settings in high-income countries.

\section{Effect of study design and country income status}

The study design had no significant effect on the estimates for either active disease or LTBI, overall or in any population subgroup. Compared to case-control studies, the odds of prevalent disease were $0.88(95 \%$ CI $0.68-1.13, p=0.31)$ in cohort studies and $1.24(95 \%$ CI $0.65-2.37, \mathrm{p}=0.51)$ in crosssectional studies. There was a significantly lower prevalence of TB overall among all studies from high-income countries

TABLE 2 Prevalence of latent tuberculosis (TB) infection in the contacts of TB patients in low-middle- and high-income countries

\begin{tabular}{|c|c|c|c|c|c|}
\hline $\begin{array}{l}\text { Included } \\
\text { studies }\end{array}$ & $\begin{array}{l}\text { Contacts with } \\
\text { latent TB infection }\end{array}$ & $\begin{array}{l}\text { Contacts } \\
\text { screenec }\end{array}$ & Proportion & $95 \% \mathrm{Cl}$ & $\tau^{2}$ \\
\hline
\end{tabular}

\section{Low-middle income}

All ages

All ${ }^{\#}$

Index patient smear positive

Index patient with HIV

Index patient XDR/MDR-TB

Household contacts

All close contacts

Contacts with HIV infection

$\leqslant 5$ yrs

5-14 yrs

$\geqslant 15 \mathrm{yrs}$

High income

All ages

All"

Index patient smear positive

Index patient with HIV

Index patient XDR/MDR-TB

Household contacts

All close contacts

Casual contacts only

Contacts with HIV infection

$\leqslant 5 \mathrm{yrs}$

$5-14$ yrs

$\geqslant 15 \mathrm{yrs}$

$\begin{array}{cr}76 & 3578 \\ 51 & 19003 \\ 12 & 1138 \\ 6 & 431 \\ 73 & 23577 \\ 73 & 2357 \\ 8 & 123 \\ 33 & 5102 \\ 21 & 6587 \\ 10 & 1198\end{array}$

1138

431

23577

23577

123

5102

6587

11980

79511

25910

131

287

20960

20213

5779

28

2093

1,407

6221

60557
33875
2376
684
49512
49643
247
12389
11123
14057

14057

284505
78784
363
554
67175
68738
27383
151
6900
4,871
12633

51.5

52.9

45.7

61.3

45.4

45.3

53.5

35.5

53.1

65.3

28.1

34.8

36.0

52.6

30.0

28.0

18.7

25.0

16.3

18.4

41.9

$\begin{array}{lll}47.1-55.8 & 0.58 & 98.9 \\ 48.9-56.8 & 0.32 & 97.7 \\ 38.7-52.9 & 0.22 & 90.9 \\ 39.1-79.6 & 1.21 & 95.2 \\ 40.7-50.2 & 0.69 & 98.4 \\ 40.6-50.1 & 0.69 & 98.4 \\ 40.6-66.0 & 0.36 & 71.4 \\ 30.3-41.1 & 0.42 & 96.6 \\ 42.0-63.9 & 1.05 & 98.6 \\ 35.5-86.5 & 3.80 & 99.6\end{array}$

24.2-32. 4

$31.2-41.0$

49.5-55.7

21.3-40.5

18.9-39.4

11.8-28.5

11.4-46.4

9.2-27.0

11.8-27.5

30.5-54.2
0.99

0.96

0.00

0.00

1.80

1.96

0.52

0.53

1.73

0.64

$1^{2}$

0.50
99.5

99.6

99.6

99.4

86.6

99.2

98.4

99.4

Data are presented as $\mathrm{n}$, unless otherwise stated. XDR: extensively drug resistant; MDR: multidrug resistant. World Bank Income Gross National Income per capita: low income ( $\leqslant \$ 1,005$ per yr); lower-middle income ( $\$ 1,006$ to $\$ 3,975$ per yr); upper-middle income ( $\$ 3,976$ to $\$ 12,275$ per yr); high income ( $\geqslant \$ 12,276$ per yr) [22]. * : [9, 32, $34,36-39,41-43,48,49,52,55,57-60,62-67,69,71,73,74,77-79,81,83-89,91,93-95,97-101,185-187,194-196,199-201$ 203-215]; ': [10, 28, 30, 31, 102, 103, $105,107,109-111,115,116,119,121-125,128-138,142-145,147-157,159-184,188,189,193,202,216-233]$. 
compared to all studies from low-middle income countries (OR 0.57, 95\% CI 0.39-0.84, p=0.005). However, there were no associations between disease prevalence and country income level for either household contacts (OR 1.40, 95\% CI $0.93-2.08, \mathrm{p}=0.10$ ) or close contacts (OR 0.55, 95\% CI $0.37-$ $0.81, \mathrm{p}=0.29)$.

\section{DISCUSSION}

Contacts exposed to patients with $\mathrm{TB}$, in a variety of settings, are at substantial risk of LTBI and active TB. The incidence of new cases is highest in the first year and remains above background incidence for at least 5 yrs after exposure to a patient with TB. The prevalence of LTBI and TB among contacts is significantly less in high-income countries than in low-middle-income countries, although this difference was not evident among household contacts. Foreign-born contacts are significantly more likely to have LTBI than locally born contacts in high-income countries.

This systematic review and meta-analysis is broader in scope than a previous meta-analysis on this topic [16]. The inclusion of data from low-, middle- and high-income countries, as well as data on prevalence and incidence in household, close contacts and congregate settings means that the findings are generalisable to most circumstances in which contact investigations are considered. We used an exact binomial approach to meta-analysis, which does not make distributional assumptions or rely on the normal approximation. Hence, our methods are broad in scope and robust in application.
A major limitation on the interpretation of the meta-analysis is the substantial heterogeneity among the studies summarised. This heterogeneity exists even within the strata and subgroups we have investigated and, therefore, must be attributable to factors that we have not investigated in this analysis. These factors may include the background prevalence of disease in the study population and differences in aspects of the study methodologies, such as inclusion criteria for contacts, time of screening relative to the time of diagnosis of the index case, methods of recruiting contacts for investigation, and diagnostic tests implemented during screening. Furthermore, some studies merged incident and prevalent cases, consequently overestimating prevalence. The confidence intervals derived from the random effects metaanalysis reflect the increased uncertainty consequent upon this heterogeneity. Nevertheless, this heterogeneity means that the summary estimates shown here need to be interpreted with caution.

There are other reasons for caution when interpreting the results. The recruitment of contacts in contact investigations is almost always incomplete and is subject to selection bias. Symptomatic contacts may be more likely than those without symptoms to comply with contact investigation. Hence, the measured prevalence of TB among contacts may overestimate the true prevalence of disease among contacts. Nevertheless, it does reflect the likely yield in contact investigations.

There is substantial risk of bias in each of the reported outcomes, owing to the observational design of most studies

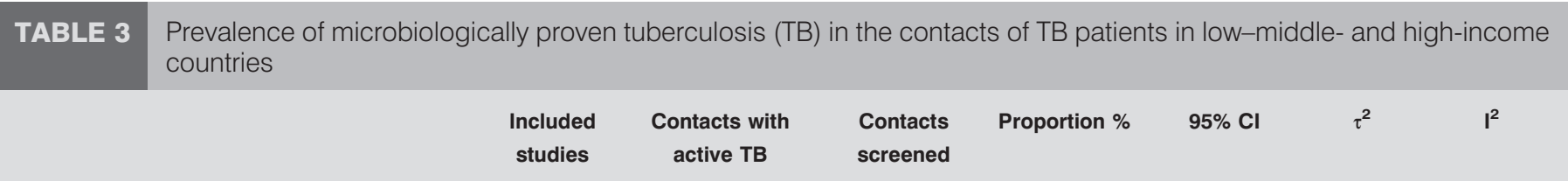

\begin{tabular}{|c|c|c|c|c|c|c|c|}
\hline \multicolumn{8}{|l|}{ Low-middle income } \\
\hline \multicolumn{8}{|l|}{ All ages } \\
\hline Index patient smear positive & 17 & 150 & 10241 & 1.2 & $0.8-1.8$ & 0.47 & 87.4 \\
\hline Index patient XDR/MDR-TB & 2 & 2 & 1056 & 0.2 & $0.0-0.8$ & 0.00 & 82.7 \\
\hline Household contacts & 36 & 8336 & 811231 & 1.4 & $1.0-2.1$ & 1.16 & 97.9 \\
\hline All close contacts & 37 & 8426 & 824541 & 1.4 & $1.0-2.1$ & 1.14 & 97.8 \\
\hline \multicolumn{8}{|l|}{ High income } \\
\hline \multicolumn{8}{|l|}{ All ages } \\
\hline All & 21 & 264 & 45897 & 0.4 & $0.2-0.7$ & 1.56 & 96.1 \\
\hline Index patient smear positive & 6 & 108 & 5970 & 0.7 & $0.3-1.9$ & 1.08 & 97.6 \\
\hline Index patient XDR/MDR-TB & 2 & 0 & 554 & 0.0 & & 0.00 & 99.9 \\
\hline Household contacts & 6 & 116 & 5459 & 1.4 & $0.8-2.5$ & 0.33 & 92.6 \\
\hline
\end{tabular}

Data are presented as $n$, unless otherwise stated. XDR: extensively drug resistant; MDR: multidrug resistant. World Bank Income Gross National Income per capita: low

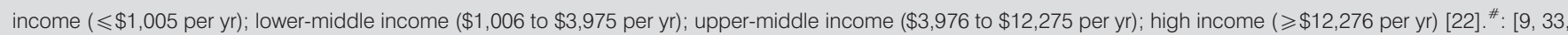
$34,38,42-46,54,56-58,60,62,63,66-68,70-73,75,76,79,82,84,85,88,90,91,95,97,99-101,234]$; ': [30, 31, 111-113, 116, 119, 120, 122, 134, 135, 137, 138, $148-150,154,165,166,170,177]$. 
and the lack of suitably matched control populations in almost all studies. Publication bias is also an important consideration in all meta-analyses. However, the usual methods for assessing bias using visual or statistical tests are only applicable to randomised controlled trials or trials with matched controls [236, 237] and not to observational studies. Therefore, we were unable to apply the formal assessments of publication bias to this analysis. It is important to consider the possibility that contact investigation with low yield may have been withheld from publication and those reporting higher prevalence of $\mathrm{TB}$ may be more likely to be available in the public domain. This possible cause for overestimation of the prevalence of $\mathrm{TB}$ in contacts should be considered when interpreting these results.

The reported data on prevalence of LTBI are subject to all of the known limitations of methods for identifying LTBI in population studies including problems due to anergy, exposure to environmental mycobacteria, and bacilli Calmette-Guérin vaccination. It is probable that the estimate of the prevalence of LTBI among HIV infected contacts is an underestimate as tests for LTBI are more likely to be falsely negative in the presence of HIV infection [185].

\section{Interpreting the findings}

Many of the patterns of TB disease and LTBI observed among contacts reflect those observed in the general population. These include findings of a higher prevalence of TB among child contacts compared with adults, and a higher prevalence of $\mathrm{TB}$ among contacts in low-middle-income countries compared with high-income countries. This explanation is also supported by the observation that there is no difference between lowmiddle- and high-income countries when analyses are limited to household contacts, because we would expect the risk in more distant, non-household contacts to be less influenced by the recent exposure to the index case and more influenced by general population risk factors.

The location of exposure to an infectious index patient is one factor that is likely to influence the risk of infection. Another is the contact's prior risk of exposure. The high prevalence of TB and LTBI among household contacts in high-income countries is likely to be explained, in part, by our finding that $36.7 \%$ of contacts investigated in high-income countries were foreign born. This is supported by other research that showed an association between the prevalence of LTBI among migrants and the prevalence of TB in the country of origin [107].

The prevalence of clinically diagnosed TB among contacts was substantially higher than the prevalence of microbiologically proven disease. It is likely that prevalence and incidence estimates based on clinically diagnosed TB are an overestimate of the true prevalence and incidence of disease. This is particularly likely among child contacts, from whom it is
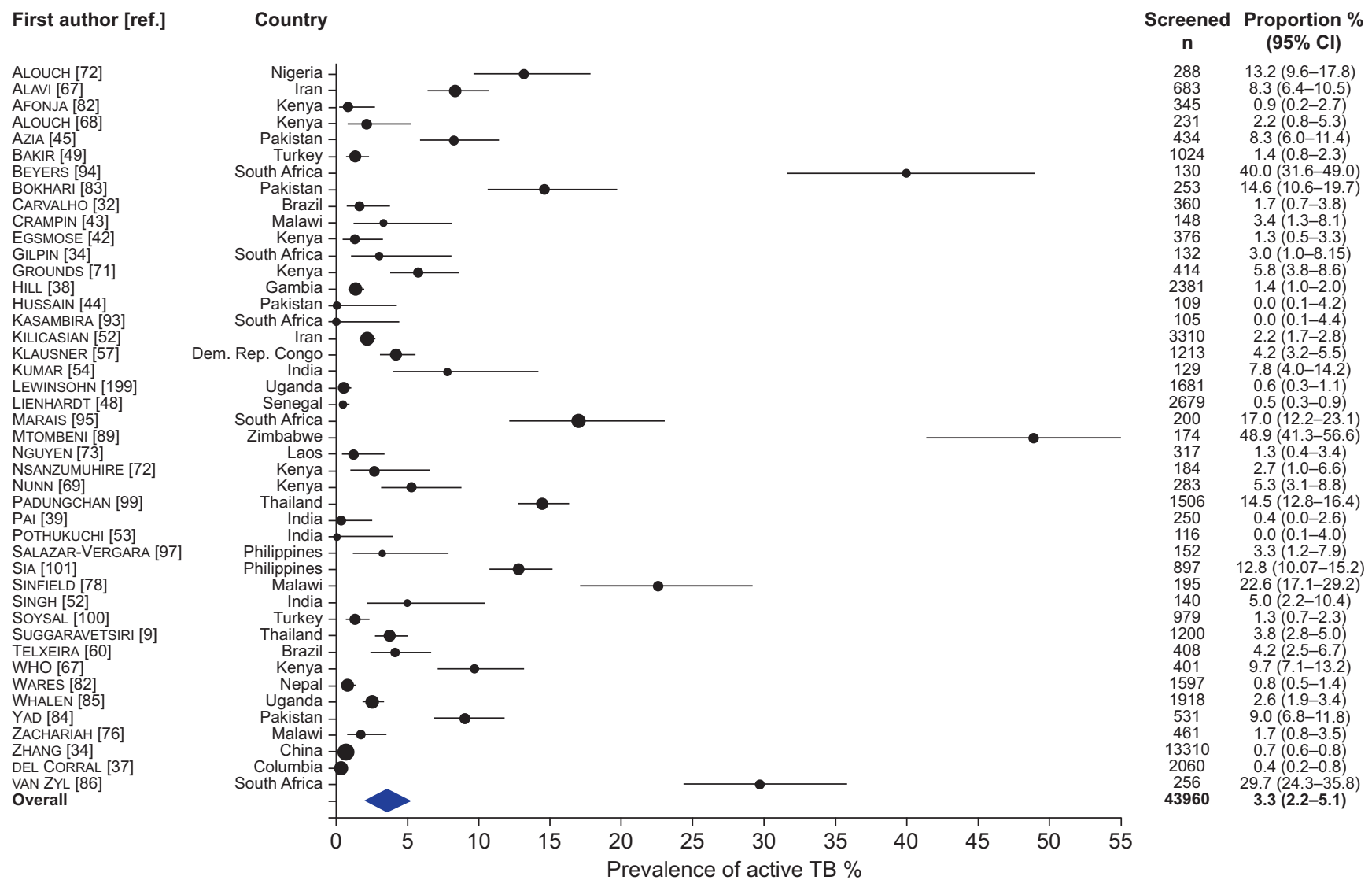

FIGURE 3. Forest plot of the prevalence of active tuberculosis (TB) among contacts of smear-positive TB in low-middle-income countries. The size of the symbols is proportional to the study sample size. 


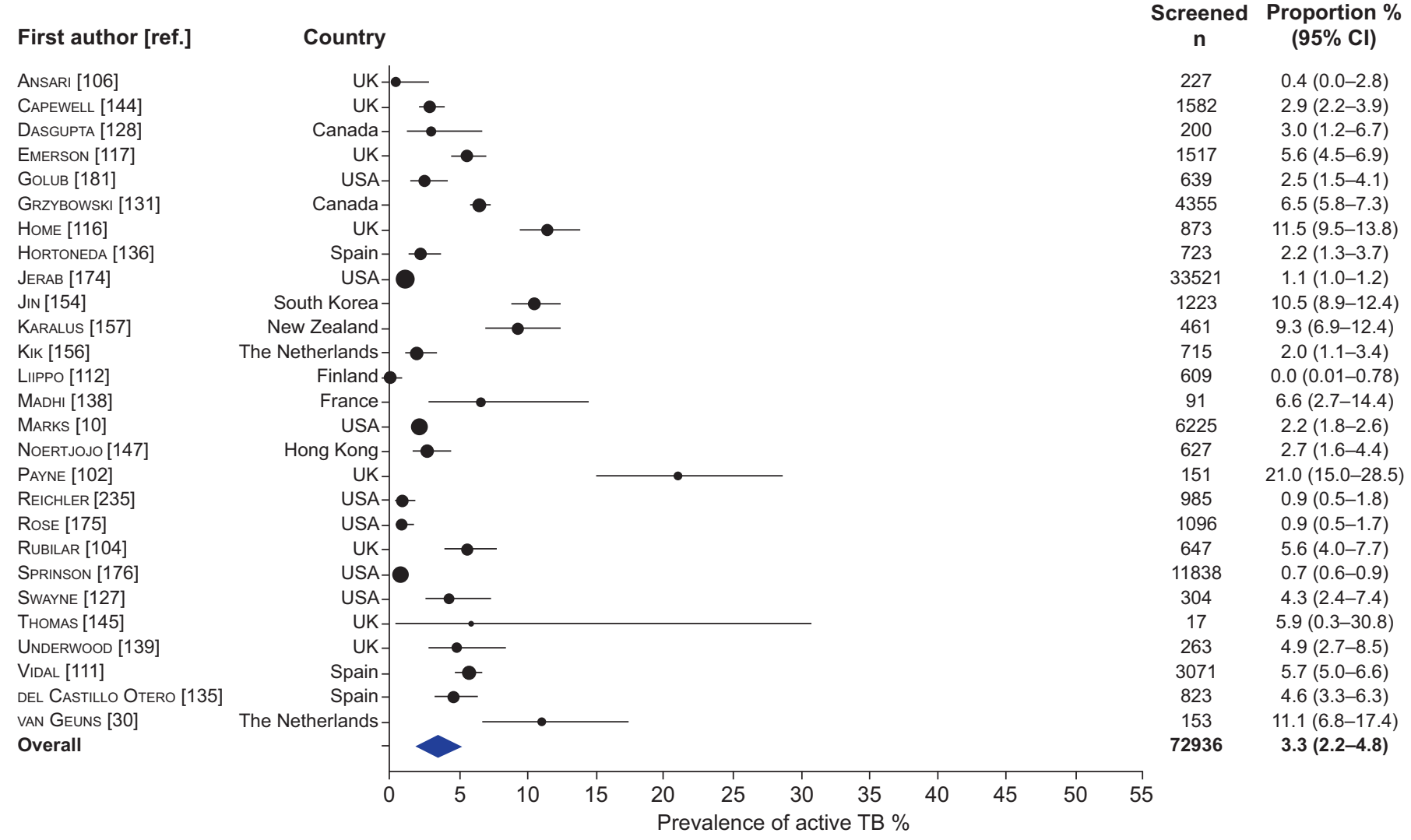

FIGURE 4. Forest plot of the prevalence of active tuberculosis (TB) among contacts of smear-positive TB in high-income countries. The size of the symbols is proportional to the study sample size.

often difficult to obtain specimens. The true burden of disease probably lies somewhere between the estimate based on clinical criteria and the estimate based on microbiological criteria.

In the absence of accurate measures of disease prevalence in the general community, it is difficult to estimate the relative contribution that transmission from index patients makes to the TB prevalence among contacts. Modern molecular epidemiology combined with conventional contact tracing has substantially clarified this issue in low-prevalence settings, where a high proportion of all isolates can be tested [108]. However, in high-prevalence countries there may be considerable difficulty in using this technique, as an insufficient proportion of cases may be captured for testing [6].
The estimated prevalence of TB among HIV infected contacts in this meta-analysis was higher than in another recent systematic review [238]. This may be because the previous review included patients "at risk" of HIV, as well as those known to be infected with HIV in the risk group. This is likely to have diluted the estimated prevalence of TB in that review.

Our analysis also shows there is a substantial ongoing risk of developing TB after the contact intervention at baseline, particularly during the first year. This risk is significantly higher in low-middle-income countries than high-income settings. This difference may be explained by the lower risk of ongoing transmission within the community in high-income countries and also the greater likelihood that contacts will have been treated for LTBI in high-income countries [109, 186, 235].

TABLE 4 Prevalence of latent tuberculosis infection (LTBI) among foreign and locally born contacts in high-income countries ${ }^{\#}$

\begin{tabular}{lccccccccc} 
Country of origin & $\begin{array}{c}\text { Included } \\
\text { studies }\end{array}$ & $\begin{array}{c}\text { Contacts } \\
\text { with LTBI }\end{array}$ & $\begin{array}{c}\text { Contacts } \\
\text { screened }\end{array}$ & $\begin{array}{c}\text { Proportion } \\
\%\end{array}$ & $\mathbf{9 5 \% ~ C l}$ & $\boldsymbol{\tau}^{\mathbf{2}}$ & $\mathbf{I}^{\mathbf{2}}$ & OR (95\% Cl) & $\mathbf{p - v a l u e}$ \\
\hline Contacts born locally & 6 & 1536 & 7576 & 17.0 & $11-8-24.0$ & 0.28 & 98.5 & 1.0 \\
Contacts born overseas & 6 & 1849 & 4298 & 39.2 & $30.0-49.3$ & 0.24 & 97.9 & $3.39(3.10-3.71)$ & $<0.0001$ \\
\hline
\end{tabular}


TABLE 5 Outcomes of contact investigation studies in congregate settings in high-income countries

\begin{tabular}{|c|c|c|c|c|c|}
\hline First author [ref.] & Country & Location of contact & Contacts tested & Prevalence of active TB \% & Prevalence of LTBI \% \\
\hline Gaensbauer [149] & Ireland & Child care centre & 268 & 6.7 & NA \\
\hline MARIENAU [164] & USA & Aeroplane flight & 861 & 0 & 24 \\
\hline Conover [221] & USA & Methadone clinic & 393 & NA & 22.3 \\
\hline Centers for Disease Control [226] & USA & Clubs with exotic dancers & 344 & NA & 29.8 \\
\hline
\end{tabular}

The incidence in the first 5 yrs may be even higher than we have estimated, as many contacts from the included studies did not complete follow-up.

\section{Policy implications for contact investigation}

The studies we reported herein are almost all observational studies. In the absence of randomised controlled trials of contact tracing it is not possible to make strong recommendations for the implementation of specific interventions [17]. Nonetheless, this review provides support for the existing priority given in WHO recommendations [239] for screening children aged $<5$ yrs and contacts with HIV infection. Our data also demonstrates that children between 5 and 14 yrs of age are at a relatively high risk of active disease and latent infection, hence this group may also benefit from additional interventions. The finding that the prevalence of TB decreases with more remote exposure lends support to the current practice of progressively implementing contact screening in concentric circles starting with household contacts and progressing through other close contacts to more remote contacts [240].

The primary goal of contact investigation is to identify disease and infection among high-risk individuals near the time of exposure. However, the contribution of contact tracing to reducing the burden of disease in the population as a whole is unclear at this time. Although recent infection is more likely to lead to disease, all individuals with latent TB infection, including those who acquired infection at a much earlier time, are at risk of reactivation. Further research, including detailed mathematical modelling applied to different epidemiological settings, will be required to estimate the impact of contact investigation on the burden of TB disease over time.

The substantial incidence of TB disease during the 5 yrs after exposure, and particularly within the first 12 months, highlights the potential importance of serial screening for TB in contacts that do not receive treatment for LTBI. An alternative to repeated screening, for low resource settings, may be providing comprehensive information to contacts about their ongoing risk of developing disease even after the index case is treated and facilitating referral in the case of contacts developing symptoms.

Contact investigation is a central component of the public health response to TB in most high-income countries [11, 241,
242]. In recent years there has been an increasing trend in lowmiddle-income countries to implement contact investigation in some form but considerable heterogeneity in the practice of it [12]. Although we have shown that the estimated prevalence of TB and LTBI is higher in low-middle-income countries than in high-income countries, it does not necessarily follow that National Tuberculosis Programmes in resource-limited settings should implement this intervention. Tuberculosis control programmes in all countries need to consider the effectiveness and cost implications of any contact investigation policies carefully. Our finding that the IRR for screening contacts in high-income settings is substantially higher than in low-middle income settings supports the current priority placed upon contact investigation in high-income countries. In order to show that contact investigation is effective in high-prevalence settings, studies must compare contact investigation to case-finding alone [19]. This will require evidence from randomised trials, such as cluster randomised controlled trials or "step-wedge" trials [243] conducted in the appropriate settings.

\section{Conclusion}

In summarising the available data on the burden of TB and LTBI among contacts of patients with TB we have highlighted the substantial heterogeneity in available estimates. Although this article does provide evidence that contacts are a high-risk group for developing $\mathrm{TB}$, policy recommendations must consider evidence of the cost-effectiveness of various contact tracing strategies, and also incorporate alternative strategies to enhance case finding. These will require investment in welldesigned, robust randomised studies conducted in relevant populations.

\section{SUPPORT STATEMENT}

This study was supported, in part, by the National Health and Medical Research Council of Australia Project Grant AppID 632781. G.J. Fox presented data from this review for a World Health Organization Expert Panel to develop guidelines for contact investigation in resource-limited settings in September 2011.

\section{STATEMENT OF INTEREST}

None declared.

\section{ACKNOWLEDGEMENTS}

C. Dobler (Woolcock Institute of Medical Research, University of Sydney, Sydney, Australia) reviewed all journal titles and abstracts, and helped to select relevant papers for inclusion. P. Hopewell 
(University of California, San Francisco, CA, USA) provided valuable advice during the preparation of this review for presentation to the World Health Organization Expert Panel for developing contact investigation recommendations.

\section{REFERENCES}

1 World Health Organization. Global tuberculosis control 2011. Geneva, WHO, 2011.

2 World Health Organization, Stop TB Partnership. The Stop TB Strategy: Building on and enhancing DOTS to meet the TB-related Millennium Development Goals. Geneva, WHO, 2006.

3 Stop TB Partnership. The Global Plan to Stop 2011-2015. Transforming the fight towards elimination of tuberculosis. Geneva, WHO, 2010.

4 Riechler HL. Contacts of tuberculosis patients in high-incidence countries. Int J Tuberc Lung Dis 2003; 7: Suppl. 3, S333-S336.

5 Greenaway C, Palayew M, Menzies D. Yield of casual contact investigation by the hour. Int J Tuberc Lung Dis 2003; 7: Suppl. 3, S479-S485.

6 Fok A, Numata Y, Schulzer M, et al. Risk factors for clustering of tuberculosis cases: a systematic review of population-based molecular epidemiology studies. Int J Tuberc Lung Dis 2008; 12: 480-492.

7 Kenyon TA, Valway SE, Walter WI, et al. Transmission of multidrug-resistant Mycobacterium tuberculosis during a long airplane flight. N Engl J Med 1996; 334: 933-938.

8 Yim J, Selvaraj P. Genetic susceptibility in tuberculosis. Respirology 2010; 15: 241-256.

9 Suggaravetsiri $\mathrm{P}$, Yanai $\mathrm{H}$, Chongsuvivatwong $\mathrm{V}$, et al. Integrated counseling and screening for tuberculosis and HIV among household contacts of tuberculosis patients in an endemic area of HIV infection: Chiang Rai, Thailand. Int J Tuberc Lung Dis 2003; 7: Suppl. 3, S424-S431.

10 Marks SM, Taylor Z, Qualls NL, et al. Outcomes of contact investigations of infectious tuberculosis patients. Am J Respir Crit Care Med 2000; 162: 2033-2038.

11 Control and prevention of tuberculosis in the United Kingdom: code of practice 2000. Joint Tuberculosis Committee of the British Thoracic Society. Thorax 2000; 55: 887-901.

12 Hwang TJ, Ottmani S, Uplekar M. A rapid assessment of prevailing policies on tuberculosis contact investigation. Int $J$ Tuberc Lung Dis 2011; 15: 1620-1623.

13 World Health Organization. International Standards for Tuberculosis Care: Diagnosis, Treatment, Public Health. The Hague, Tuberculosis Coalition for Technical Assistance, 2006.

14 World Health Organization. WHO Three I's Meeting. Geneva, Switzerland, 2008.

15 World Health Organization. Recommendations for investigating contacts of persons with infectious tuberculosis in low and middle-income countries. WHO/HTM/TB/2012.9. Geneva, WHO, 2012.

16 Morrison J, Pai M, Hopewell PC. Tuberculosis and latent tuberculosis infection in close contacts of people with pulmonary tuberculosis in low-income and middle-income countries: a systematic review and meta-analysis. Lancet Infect Dis 2008; 8: 359-368.

17 Guyatt GHG, Oxman A, Vist G, et al. GRADE: an emerging consensus on rating quality of evidence and strength of recommendations. BMJ 2008; 336: 924-926.

18 Liberati A, Altman DG, Tetzlaff J, et al. The PRISMA statement for reporting systematic reviews and meta-analyses of studies that evaluate healthcare interventions: explanation and elaboration. BMJ 2009; 339: b2700.
19 Fox GJ, Dobler CC, Marks GB. Active case finding in contacts of people with tuberculosis. Cochrane Database Syst Rev 2011; 9: CD008477.

20 Liu E, Cheng S, Wang X, et al. A systematic review of the investigation and management of close contacts of tuberculosis in China. J Public Health (Oxf) 2010; 32: 461-466.

21 Mulder C, Klinkenberg E, Manissero D. Effectiveness of tuberculosis contact tracing among migrants and the foreignborn population. Euro Surveill 2009; 14: 19153.

22 The World Bank. Data. How we Classify Countries. http://data. worldbank.org/about/country-classifications Date last accessed: November 1, 2012.

23 Fleiss J, ed. Statistical methods for rates and proportions. 2nd Edn. New York, John Wiley \& Sons, 1981; pp. 14-15.

24 Hamza TH, van Houwelingen HC, Stijnen T. The binomial distribution of meta-analysis was preferred to model withinstudy variability. J Clin Epidemiol 2008; 61: 41-51.

25 The World Bank. Data. Incidence of tuberculosis per 100,000 people. http:/ / data.worldbank.org/indicator/SH.TBS.INCD Date last accessed: November 1, 2012.

26 Higgins JP, Thompson SG, Deeks JJ, et al. Measuring inconsistency in meta-analyses. BMJ 2003; 327: 557-560.

27 Riley RD, Higgins JPT, Deeks JJ. Interpretation of random effects meta-analyses. BMJ 2009; 342: d549.

28 Mixides G, Shende V, Teeter LD, et al. Number of negative acidfast smears needed to adequately assess infectivity of patients with pulmonary tuberculosis. Chest 2005; 128: 108-115.

29 Diel R, Loddenkemper R, Meywald-Walter K, et al. Comparative performance of tuberculin skin test, QuantiFERON-TB-Gold In Tube assay, and T-Spot.TB test in contact investigations for tuberculosis. Chest 2009; 135: 1010-1018.

30 van Geuns HA, Meijer J, Styblo K. Results of contact examination in Rotterdam, 1967-1969. Bull Int Union Tuberc 1975; 50: 107-121.

31 Snider DE Jr, Kelly GD, Cauthen GM, et al. Infection and disease among contacts of tuberculosis cases with drug-resistant and drug-susceptible bacilli. Am Rev Respir Dis 1985; 132: 125-132.

32 Carvalho AC, DeRiemer K, Nunes ZB, et al. Transmission of Mycobacterium tuberculosis to contacts of HIV-infected tuberculosis patients. Am J Respir Crit Care Med 2001; 164: 2166-2171.

33 Zhang X, Wei X, Zou G, et al. Evaluation of active tuberculosis case finding through symptom screening and sputum microscopy of close contacts in Shandong, China. Trop Med Int Health 2011.

34 Gilpin TP, Hammond M. Active case-finding - for the whole community or for tuberculosis contacts only? S Afr Med J 1987; 72: 260-262.

35 Becerra MC, Appleton SC, Franke MF, et al. Tuberculosis burden in households of patients with multidrug-resistant and extensively drug-resistant tuberculosis: a retrospective cohort study. Lancet 2011; 377: 147-152.

36 Lemos AC, Matos ED, Pedral-Sampaio DB, et al. Risk of tuberculosis among household contacts in Salvador, Bahia. Braz J Infect Dis 2004; 8: 424-430.

37 del Corral H, Paris SC, Marin ND, et al. IFN-gamma response to Mycobacterium tuberculosis, risk of infection and disease in household contacts of tuberculosis patients in Colombia. PLoS One 2009; 4: e8257.

38 Hill PC, Jackson-Sillah DJ, Fox A, et al. Incidence of tuberculosis and the predictive value of ELISPOT and Mantoux tests in Gambian case contacts. PLoS Med 2008; 3: e1379.

39 Pai M, Joshi R, Dogra S, et al. T-cell assay conversions and reversions among household contacts of tuberculosis patients in rural India. Int J Tuberc Lung Dis 2009; 13: 84-92.

40 Ramakrishnan CV, Andrews RH, Devadatta S, et al. Influence of segregation to tuberculous patients for one year on the attack 
rate of tuberculosis in a 2-year period in close family contacts in South India. Bull World Health Organ 1961; 24: 129-148.

41 Kamat SR, Dawson JJ, Devadatta S, et al. A controlled study of the influence of segregation of tuberculous patients for one year on the attack rate of tuberculosis in a 5-year period in close family contacts in South India. Bull World Health Organ 1966; 34: 517-532.

42 Egsmose T, Ang'awa JO, Poti SJ. The use of isoniazid among household contacts of open cases of pulmonary tuberculosis. Bull World Health Organ 1965; 33: 419-433.

43 Crampin A, Kasimba S, Mwaungulu NJ, et al. Married to $M$. tuberculosis: risk of infection and disease in spouses of smearpositive tuberculosis patients. Trop Med Int Health 2011; 16: 811-818.

44 Hussain R, Talat N, Shahid F, et al. Longitudinal tracking of cytokines after acute exposure to tuberculosis: association of distinct cytokine patterns with protection and disease development. Clin Vaccine Immunol 2007; 14: 1578-1586.

45 Aziz A, Ishaq M, Akhwand R. Infection risk of sputum positive tuberculosis patients to their family contacts with and without chemotherapy. J Pak Med Assoc 1985; 35: 249-252.

46 Bayona J, Chavez-Pachas AM, Palacios E, et al. Contact investigations as a means of detection and timely treatment of persons with infectious multidrug-resistant tuberculosis. Int J Tuberc Lung Dis 2003; 7: Suppl. 3, S501-S509.

47 Grandjean L, Crossa A, Gilman RH, et al. Tuberculosis in household contacts of multidrug-resistant tuberculosis patients. Int J Tuberc Lung Dis 2011; 15: 1164-1169.

48 Lienhardt C, Fielding K, Hane AA, et al. Evaluation of the prognostic value of IFN-gamma release assay and tuberculin skin test in household contacts of infectious tuberculosis cases in Senegal. PLoS One 2010; 5: e10508.

49 Bakir M, Millington KA, Soysal A, et al. Prognostic value of a Tcell-based, interferon-gamma biomarker in children with tuberculosis contact. Ann Intern Med 2008; 149: 777-787.

50 Kilicaslan Z, Kiyan E, Kucuk C, et al. Risk of active tuberculosis in adult household contacts of smear-positive pulmonary tuberculosis cases. Int J Tuberc Lung Dis 2009; 13: 93-98.

51 Pothukuchi M, Nagaraja SB, Kelamane S, et al. Tuberculosis contact screening and isoniazid preventive therapy in a South Indian district: operational issues for programmatic consideration. PLoS One 2011; 6: e22500.

52 Singh M, Mynak ML, Kumar L, et al. Prevalence and risk factors for transmission of infection among children in household contact with adults having pulmonary tuberculosis. Arch Dis Child 2005; 90: 624-628.

53 Warawdekar MS, Shah JR. Pulmonary tuberculosis in the contacts: a mass miniature roentgenographic study. Indian J Med Sci 1958; 12: 797-801.

54 Kumar RA, Saran M, Verma BL, et al. Pulmonary tuberculosis among contacts of patients with tuberculosis in an urban Indian population. J Epidemiol Community Health 1984; 38: 253-258.

55 Dahiwale N, Rao S, Singh J, et al. Significance of family survey of index case for detection of tuberculosis. Indian Pediatr 2011; 48: 387-389.

56 Eckhoff CT. Evaluation of a clinical index among adult contacts of children with tuberculosis in rural Haiti. Int J Tuberc Lung Dis 2000; 4: 1143-1148.

57 Klausner JD, Ryder RW, Baende E, et al. Mycobacterium tuberculosis in household contacts of human immunodeficiency virus type 1-seropositive patients with active pulmonary tuberculosis in Kinshasa, Zaire. J Infect Dis 1993; 168: 106-111.

58 Lin X, Chongsuvivatwong V, Lin L, et al. Dose-response relationship between treatment delay of smear-positive tuberculosis patients and intra-household transmission: a cross-sectional study. Trans R Soc Trop Med Hyg 2008; 102: 797-804.
59 Kenyon TA, Creek T, Laserson $\mathrm{K}$, et al. Risk factors for transmission of Mycobacterium tuberculosis from HIV-infected tuberculosis patients, Botswana. Int J Tuberc Lung Dis 2002; 6: 843-850.

60 Teixeira L, Perkins MD, Johnson JL, et al. Infection and disease among household contacts of patients with multidrug-resistant tuberculosis. Int J Tuberc Lung Dis 2001; 5: 321-328.

61 Cavalcante SC, Durovni B, Barnes GL, et al. Communityrandomized trial of enhanced DOTS for tuberculosis control in Rio de Janeiro, Brazil. Int J Tuberc Lung Dis 2010; 14: 203-209.

62 Machado A Jr, Emodi K, Takenami I, et al. Analysis of discordance between the tuberculin skin test and the interferon-gamma release assay. Int J Tuberc Lung Dis 2009; 13: 446-453.

63 Kritski AL, Marquez MJO, Rabahi MF, et al. Transmission of tuberculosis to close contacts of patients with multidrugresistant tuberculosis. Am J Respir Crit Care Med 1996; 153: 331-335.

64 Militao de Albuquerque Mde F, Ximenes RA, Campelo AR, et al. Neonatal BCG vaccine and response to the tuberculin test in BCG vaccinated children in contact with tuberculosis patients in Recife, Brazil. J Trop Pediatr 2004; 50: 32-36.

65 Alavi SM, Farahmand FM. Pulmonary tuberculosis in household contact of patients with active tuberculosis in Ahwaz, Iran (20032005). Pak J Med Sci 2008; 24: 780-785.

66 Khalilzadeh S, Masjedi H, Hosseini M, et al. Transmission of Mycobacterium tuberculosis to households of tuberculosis patients: a comprehensive contact tracing study. Arch Iran Med 2006; 9: 208-212.

67 WHO Tuberculosis Chemotherapy Centre. An investigation of household contacts of open cases of pulmonary tuberculosis amongst the Kikuyu in Kiambu, Kenya. Bull World Health Organ 1961; 25: 831-850.

68 Aluoch JA, Edwards EA, Stott H. A fourth study of case-finding methods for pulmonary tuberculosis in Kenya. Trans $R$ Soc Trop Med Hyg 1982; 76: 679-691.

69 Nunn P, Mungai M, Nyamwaya J, et al. The effect of human immunodeficiency virus type- 1 on the infectiousness of tuberculosis. Tuber Lung Dis 1994; 75: 25-32.

70 Aluoch JA, Karuga WK, Nsanzumuhire H, et al. A second study of the use of community leaders in case-finding for pulmonary tuberculosis in Kenya. Tubercle 1978; 59: 233-243.

71 Grounds JG. The contacts of cases of open pulmonary tuberculosis in Kisii, Kenya. East Afr Med J 1964; 41: 20-25.

72 Nsanzumuhire $\mathrm{H}$, Aluoch JA, Karuga WK, et al. A third study of case-finding methods for pulmonary tuberculosis in Kenya, including the use of community leaders. Tubercle 1981; 62: 79-94.

73 Nguyen TH, Odermatt P, Slesak G, et al. Risk of latent tuberculosis infection in children living in households with tuberculosis patients: a cross sectional survey in remote northern Lao People's Democratic Republic. BMC Infect Dis 2009; 9: 96.

74 Azar JE. Source detection and contact investigation in tuberculosis control. Doc Med Geogr Trop 1957; 9: 45-51.

75 Ottmani S, Zignol M, Bencheikh N, et al. TB contact investigations: 12 years of experience in the National TB Programme, Morocco 1993-2004. East Mediterr Health J 2009; 15: 494-503.

76 Zachariah R, Spielmann MP, Harries AD, et al. Passive versus active tuberculosis case finding and isoniazid preventive therapy among household contacts in a rural district of Malawi. Int J Tuberc Lung Dis 2003; 7: 1033-1039.

77 Topley JM, Maher D, Mbewe LN. Transmission of tuberculosis to contacts of sputum positive adults in Malawi. Arch Dis Child 1996; 74: 140-143. 
78 Sinfield R, Nyirenda M, Haves $S$, et al. Risk factors for TB infection and disease in young childhood contacts in Malawi. Ann Trop Paediatr 2006; 26: 205-213.

79 Naing NN, Mohammad WZW, Salleh R, et al. A multi-centered study of the influence of HIV on transmission of tuberculosis to household contacts in three states of Malaysia. Int Med J 2007; 14: 273-279.

80 Afonja AO, Labode MO, Edet EG. Early yield of pulmonary tuberculosis among household contacts of known cases of open pulmonary tuberculosis in Lagos. East Afr Med J 1973; 50: 136-139.

81 Akenzua G, Oviawe O. Cost-benefit of contact-tracing in a tuberculosis programme. Niger J Paediatr 1984; 11: 81-85.

82 Wares DF, Akhtar M, Singh S, et al. Is TB contact screening relevant in a developing country setting? Experiences from eastern Nepal, 1996-1998. Int J Tuberc Lung Dis 2000; 4: 920-924.

83 Bokhari SY, Ahmad A, Shaikh MY, et al. A study of tuberculosis contacts. J Pak Med Assoc 1987; 37: 48-52.

$84 \mathrm{Yad}$ MI. Observations on the examination of contacts of tuberculosis patients - a 15 year study (1953-67). Bull Int Union Tuberc 1974; 49: Suppl. 1, 261-266.

85 Whalen CC, Zalwango S, Chiunda A, et al. Secondary attack rate of tuberculosis in urban households in Kampala, Uganda. PLoS One 2011; 6: e16137.

86 van Zyl S, Marais BJ, Hesseling AC, et al. Adherence to antituberculosis chemoprophylaxis and treatment in children. Int $J$ Tuberc Lung Dis 2006; 10: 13-18.

87 Schaaf HS, Gie RP, Kennedy M, et al. Evaluation of young children in contact with adult multidrug-resistant pulmonary tuberculosis: a 30-month follow-up. Pediatrics 2002; 109: 765-771.

88 Elliott AM, Hayes RJ, Halwiindi B, et al. The impact of HIV on infectiousness of pulmonary tuberculosis: a community study in Zambia. AIDS 1993; 7: 981-987.

89 Mtombeni S, Mahomva A, Siziya S, et al. A clinical evaluation of children under the age of five years who are household contacts of adults with sputum positive tuberculosis in Harare, Zimbabwe. Cent Afr J Med 2002; 48: 28-32.

90 Vella V, Racalbuto V, Guerra R, et al. Household contact investigation of multidrug-resistant and extensively drug-resistant tuberculosis in a high HIV prevalence setting. Int J Tuberc Lung Dis 2011; 15: 1170-1175.

91 Kruk A, Gie RP, Schaaf HS, et al. Symptom-based screening of child tuberculosis contacts: improved feasibility in resourcelimited settings. Pediatrics 2008; 121: e1646-e1652.

92 Saunders LD, Irwig LM, Wilson TD, et al. Tuberculosis management in Soweto. South Afr Med J 1984; 66: 330-333.

93 Kasambira TS, Shah M, Adrian PV, et al. QuantiFERON-TB gold in-tube for the detection of Mycobacterium tuberculosis infection in children with household tuberculosis contact. Int J Tuberc Lung Dis 2011; 15: 628-634.

94 Beyers N, Gie RP, Schaaf HS, et al. A prospective evaluation of children under the age of 5 years living in the same household as adults with recently diagnosed pulmonary tuberculosis. Int $J$ Tuberc Lung Dis 1997; 1: 38-43.

95 Marais BJ, Hesseling AC, Schaaf HS, et al. Mycobacterium tuberculosis transmission is not related to household genotype in a setting of high endemicity. J Clin Microbiol 2009; 47: 1338-1343.

96 Becerra MC, Pachao-Torreblanca IF, Bayona J, et al. Expanding tuberculosis case detection by screening household contacts. Public Health Rep 2005; 120: 271-277.

97 Salazar-Vergara RM, Sia IG, Tupasi TE, et al. Tuberculosis infection and disease in children living in households of Filipino patients with tuberculosis: a preliminary report. Int J Tuberc Lung Dis 2003; 7: Suppl. 3, S494-S500.
98 Fuimaono A, Vince J. Screening contacts of children with tuberculosis: an important and worthwhile part of case management. P N G Med J 1997; 40: 69-73.

99 Padungchan S, Konjanart S, Kasiratta S, et al. The effectiveness of $B C G$ vaccination of the newborn against childhood tuberculosis in Bangkok. Bull World Health Organ 1986; 64: 247-258.

100 Soysal A, Millington KA, Bakir M, et al. Effect of BCG vaccination on risk of Mycobacterium tuberculosis infection in children with household tuberculosis contact: a prospective community-based study. Lancet 2005; 366: 1443-1451.

101 Sia IG, Orillaza RB, St Sauver JL, et al. Tuberculosis attributed to household contacts in the Philippines. Int J Tuberc Lung Dis 2010; 14: $122-125$.

102 Payne CR. Surveillance of tuberculosis contacts: experience at Ealing Chest Clinic. Tubercle 1978; 59: 179-184.

103 Loudon RG, Williamson J, Johnson JM. An analysis of 3,485 tuberculosis contacts in the city of Edinburgh during 1954-1955. Am Rev Tuberc 1958; 77: 623-643.

104 Rubilar M, Brochwicz-Lewinski MJ, Anderson M, et al. The outcome of contact procedures for tuberculosis in Edinburgh, Scotland 1982-1991. Respir Med 1995; 89: 113-120.

105 Hussain SF, Watura R, Cashman B, et al. Audit of a tuberculosis contact tracing clinic. BMJ 1992; 304: 1213-1215.

106 Ansari S, Thomas S, Campbell IA, et al. Refined tuberculosis contact tracing in a low incidence area. Respir Med 1998; 92: 1127-1131.

107 Aissa K, Madhi F, Ronsin N, et al. Evaluation of a model for efficient screening of tuberculosis contact subjects. Am J Respir Crit Care Med 2008; 177: 1041-1047.

108 Borrell S, Espanol M, Orcau A, et al. Factors associated with differences between conventional contact tracing and molecular epidemiology in study of tuberculosis transmission and analysis in the city of Barcelona, Spain. J Clin Microbiol 2009; 47: 198-204.

109 Chee CB, Teleman MD, Boudville IC, et al. Treatment of latent TB infection for close contacts as a complementary TB control strategy in Singapore. Int J Tuberc Lung Dis 2004; 8: 226-231.

110 Janssens JP, Roux-Lombard P, Perneger T, et al. Contribution of a IFN-gamma assay in contact tracing for tuberculosis in a lowincidence, high immigration area. Swiss Med Wkly 2008; 138: 585-593.

111 Vidal R, Miravitlles M, Cayla JA, et al. Increased risk of tuberculosis transmission in families with microepidemics. Eur Respir J 1997; 10: 1327-1331.

112 Liippo KK, Kulmala K, Tala EO. Focusing tuberculosis contact tracing by smear grading of index cases. Am Rev Respir Dis 1993; 148: 235-236.

113 Selby CD, Allen MB, Leitch AG. Optimal duration of radiological follow-up for tuberculosis contacts. Respir Med 1989; 83: 353-355.

114 Teale C, Cundall DB, Pearson SB. Time of development of tuberculosis in contacts. Respir Med 1991; 85: 475-477.

115 Neely F, Maguire H, Le Brun F, et al. High rate of transmission among contacts in large London outbreak of isoniazid mono-resistant tuberculosis. J Public Health (Oxf) 2010; 32: $44-51$.

116 Horne NW, Davies BH, Pines A. A study of a standardised contact procedure in tuberculosis. Tubercle 1978; 59: 245-259.

117 Emerson PA. Tuberculosis contacts in north-west London. Tubercle 1959; 40: 177-180.

118 Ormerod LP, Green RM, Broadfield E. Outcome for adult contacts of smear-positive pulmonary tuberculosis in the absence of X-ray follow-up: 2000-03. Commun Dis Public Health 2004; 7: 132-133.

119 Esmonde TF, Petheram IS. Audit of tuberculosis contact tracing procedures in south Gwent. Respir Med 1991; 85: 421-424. 
120 Ormerod LP. Results of tuberculosis contact tracing: Blackburn 1982-90. Respir Med 1993; 87: 127-131.

121 Ling DL, Liaw YP, Lee CY, et al. Contact investigation for tuberculosis in Taiwan contacts aged under 20 years in 2005. Int J Tuberc Lung Dis 2011; 15: 50-55.

122 Yoshiyama $\mathrm{T}$, Harada N, Higuchi $\mathrm{K}$, et al. Use of the QuantiFERON-TB Gold test for screening tuberculosis contacts and predicting active disease. Int J Tuberc Lung Dis 2010; 14: 819-827.

123 Bush OB Jr, Sugimoto M, Fujii Y, et al. Isoniazid prophylaxis in contacts of persons with known tuberculosis. Second report. Am Rev Respir Dis 1965; 92: 732-740.

$124 \mathrm{Chen} \mathrm{CH}$, Goh EH. The management of household contacts of active pulmonary tuberculosis in Singapore. Ann Acad Med Singapore 1981; 10: 242-247.

125 Ferebee SH, Mount FW. Tuberculosis morbidity in a controlled trial of the prophylactic use of isoniazid among household contacts. Am Rev Respir Dis 1962; 85: 490-510.

126 Mount FW, Ferebee SH. The effect of isoniazid prophylaxis on tuberculosis morbidity among household contacts of previously known cases of tuberculosis. Am Rev Respir Dis 1962; 85: 821-827.

127 Swayne JB, Tepper L. Tuberculosis contact follow-up in the Los Angeles City health department. Am J Public Health Nations Health 1964; 54: 1270-1281.

128 Dasgupta K, Schwartzman K, Marchand R, et al. Comparison of cost-effectiveness of tuberculosis screening of close contacts and foreign-born populations. Am J Respir Crit Care Med 2000; 162 2079-2086.

129 Yeo IKT, Tannenbaum T, Scott AN, et al. Contact investigation and genotyping to identify tuberculosis transmission to children. Pediatr Infect Dis J 2006; 25: 1037-1043.

130 MacIntyre CR, Plant AJ. Impact of policy and practice on the effectiveness of contact screening for tuberculosis. Prev Med 1998; 27: 830-837.

131 Grzybowski S, Barnett GD, Styblo K. Contacts of cases of active pulmonary tuberculosis. Bull Int Union Tuberc 1975; 50: 90-106.

132 Temple A. The results of routine examination of tuberculosis contacts. Can Med Assoc J 1935; 33: 507-509.

133 Lankensjold E, Herrmann FR, Luong BL, et al. Contact tracing for tuberculosis and treatment for latent infection in a low incidence country. Swiss Medical Weekly 2008; 138: 78-84.

134 Casanova C, Gonzalez C, Perez M, et al. Contact screening in tuberculous pediatric patients. Pediatr Infect Dis J 1996; 15: 277.

135 del Castillo Otero D, Penafiel Colas M, Alvarez Gutierrez F, et al. Investigation of tuberculosis contacts in a nonhospital pneumology practice. Eur J Clin Microbiol Infect Dis 1999; 18: 790-795.

136 Hortoneda M, Saiz C, Alfonso JI, et al. Prevention and early detection of tuberculosis. Eur J Epidemiol 1996; 12: 413-419.

137 Uhari M, Linna O. Close contact with tuberculosis in childhood. Eur J Respir Dis 1982; 63: 579-583.

138 Madhi F, Fuhrman C, Monnet I, et al. Transmission of tuberculosis from adults to children in a Paris suburb. Pediatr Pulmonol 2002; 34: 159-163.

139 Underwood BR, White VLC, Baker T, et al. Contact tracing and population screening for tuberculosis. Who should be assessed? J Pub Health Med 2003; 25: 59-61.

140 Thompson BC. Tuberculosis home contacts; a technique of routine examination at Ealing Chest Clinic. Nurs Times 1946; 42 188.

141 Miller RF, Kent RJ, Uttley AHC, et al. Transmission of tuberculosis in patients with HIV infection. BMJ 1995; 310: 401.

142 Dick WP, Thompson BC. Examination of home-contacts of tuberculous persons. Lancet 1946; 2: 791-793.
143 Davies PD. The natural history of tuberculosis in children. A study of child contacts in the Brompton Hospital Child Contact Clinic from 1930 to 1952. Tubercle 1961; 42: 1-40.

144 Capewell S, Leitch AG. The value of contact procedures for tuberculosis in Edinburgh. Br J Dis Chest 1984; 78: 317-329.

145 Thomas B, Pugalenthi A, Patel H, et al. Concordance between tuberculin skin test and interferon-gamma assay and interferongamma response to mitogen in pediatric tuberculosis contacts. Pediatr Pulmonol 2011; 46: 1225-1232.

146 Wang PD, Lin RS. Tuberculosis transmission in the family. J Infect 2000; 41: 249-251.

147 Noertjojo K, Tam CM, Chan SL, et al. Contact examination for tuberculosis in Hong Kong is useful. Int J Tuberc Lung Dis 2002; 6: 19-24.

148 Huang YW, Shen GH, Lee JJ, et al. Latent tuberculosis infection among close contacts of multidrug-resistant tuberculosis patients in central Taiwan. Int J Tuberc Lung Dis 2010; 14: 1430-1435.

149 Lee MS, Leung CC, Kam KM, et al. Early and late tuberculosis risks among close contacts in Hong Kong. Int J Tuberc Lung Dis 2008; 12: 281-287.

150 Gaensbauer JT, Vandaleur M, O'Neil M, et al. BCG protects toddlers during a tuberculosis outbreak. Arch Dis Child 2009; 94 392-393.

151 Attamna A, Chemtob D, Attamna S, et al. Risk of tuberculosis in close contacts of patients with multidrug resistant tuberculosis: a nationwide cohort. Thorax 2009; 64: 271.

152 Moro ML, Errante I, Infuso A, et al. Effectiveness of infection control measures in controlling a nosocomial outbreak of multidrug-resistant tuberculosis among HIV patients in Italy. Int J Tuberc Lung Dis 2000; 4: 61-68.

153 Hirama T, Hagiwara K, Kanazawa M. Tuberculosis screening programme using the QuantiFERON-TB Gold test and chest computed tomography for healthcare workers accidentally exposed to patients with tuberculosis. J Hosp Infect 2011; 77: 257-262.

154 Jin BW, Hong YP, Kim SJ. A contact study to evaluate the BCG vaccination programme in Seoul. Tubercle 1989; 70: 241-248.

155 Verver S, van Loenhout-Rooyackers $\mathrm{JH}$, Bwire $\mathrm{R}$, et al. Tuberculosis infection in children who are contacts of immigrant tuberculosis patients. Eur Respir J 2005; 26: 126-132.

156 Kik SV, Franken WP, Arend SM, et al. Interferon- $\gamma$ release assays in immigrant contacts and effect of remote exposure to Mycobacterium tuberculosis. Int J Tuberc Lung Dis 2009; 13: 820-828.

157 Karalus NC. Contact screening procedures for tuberculosis in Auckland. N Z Med J 1988; 101: 45-49.

158 Calder L, Priest P. One year of tuberculosis in Auckland. NZ Med J 1996; 109: 164-167.

159 Chee CBE, Teleman MD, Boudville IC, et al. Contact screening and latent $\mathrm{TB}$ infection treatment in Singapore correctional facilities. Int J Tuberc Lung Dis 2005; 9: 1248-1252.

160 Webb RM, Holcombe M, Pearson MM. Tuberculosis contact investigation in a rural state. Int J Tuberc Lung Dis 2003; 7: Suppl. 3, S353-S357.

161 Yun LW, Reves RR, Reichler MR, et al. Outcomes of contact investigation among homeless persons with infectious tuberculosis. Int J Tuberc Lung Dis 2003; 7: Suppl. 3, S405-S411.

162 Vennema A. Contact investigation and isoniazid chemoprophylaxis in New York City, 1979-1987. NY State J Med 1992; 92 185-188.

163 Wells CD, Zuber PL, Nolan CM, et al. Tuberculosis prevention among foreign-born persons in Seattle-King County, Washington. Am J Respir Crit Care Med 1997; 156: 573-577. 
164 Gross TP, Silverman PR, Bloch AB, et al. An outbreak of tuberculosis in rural Delaware. Am J Epidemiol 1989; 129: 362-371.

165 Marienau KJ, Burgess GW, Cramer E, et al. Tuberculosis investigations associated with air travel: U.S. Centers for Disease Control and Prevention, January 2007 June 2008. Travel Med Infect Dis 2010; 8: 104-112.

166 Behr MA, Hopewell PC, Paz EA, et al. Predictive value of contact investigation for identifying recent transmission of $\mathrm{Myco-}$ bacterium tuberculosis. Am J Respir Crit Care Med 1998; 158: 465-469.

167 Davidow AL, Mangura BT, Wolman MS, et al. Workplace contact investigations in the United States. Int J Tuberc Lung Dis 2003; 7: Suppl. 3, S446-S452.

168 Driver CR, Balcewicz-Sablinska MK, Kim Z, et al. Contact investigations in congregate settings, New York City. Int $J$ Tuberc Lung Dis 2003; 7: Suppl. 3, S432-S438.

169 Moonan PK, Marruffo M, Manguia-Bayona G, et al. Tuberculosis: what is the yield of associate investigations in non-BCGimmunized children with positive tuberculin skin tests? Int $J$ Tuberc Lung Dis 2005; 9: 322-327.

170 Lofy KH, McElroy PD, Lake L, et al. Outbreak of tuberculosis in a homeless population involving multiple sites of transmission. Int J Tuberc Lung Dis 2006; 10: 683-689.

171 Centers for Disease Control and Prevention. Tuberculosis outbreak in a low-incidence state - Indiana, 2001-2004. MMWR Morb Mortal Wkly Rep 2004; 53: 1134-1135.

172 Gerald LB, Tang S, Bruce F, et al. A decision tree for tuberculosis contact investigation. Am J Respir Crit Care Med 2002; 166: $1122-1127$.

173 Cruz AT, Medina D, Whaley EM, et al. Tuberculosis among families of children with suspected tuberculosis and employees at a children's hospital. Infect Control Hosp Epidemiol 2011; 32: 188-190.

174 Jereb J, Etkind SC, Joglar OT, et al. Tuberculosis contact investigations: outcomes in selected areas of the United States, 1999. Int J Tuberc Lung Dis 2003; 7: Suppl. 3, S384-S390.

175 Rose CE Jr, Zerbe GO, Lantz SO, et al. Establishing priority during investigation of tuberculosis contacts. Am Rev Respir Dis 1979; 119: 603-609.

176 Sprinson JE, Flood J, Fan CS, et al. Evaluation of tuberculosis contact investigations in California. Int J Tuberc Lung Dis 2003; 7: Suppl. 3, S363-368.

177 Gessner BD, Weiss NS, Nolan CM. Risk factors for pediatric tuberculosis infection and disease after household exposure to adult index cases in Alaska. J Pediatr 1998; 132: 509-513.

178 Greenberg HB, Trachtman L, Thompson DH. Finding recent tuberculous infection in New Orleans. Results of tuberculin skin tests on New Orleans children from the inner city and Contact Investigation Program. JAMA 1976; 235: 931-932.

179 Li J, Marks SM, Driver CR, et al. Human immunodeficiency virus counseling, testing, and referral of close contacts to patients with pulmonary tuberculosis: feasibility and costs. J Public Health Manag Pract 2007; 13: 252-262.

180 Geiger FL, Kuemmerer JM. Tuberculosis casefinding among contacts in seven south carolina counties. Public Health Rep 1963; 78: 663-668.

181 Golub J, Bur S, Cronin WA, et al. Delayed tuberculosis diagnosis and tuberculosis transmission. Int J Tuberc Lung Dis 2006; 10: 24-30.

182 Ruben FL, Lynch DC. Tuberculosis control through contact investigation. $\mathrm{Pa}$ Med 1996; 99: 22-23.

183 Reichler MR, Reves R, Bur S, et al. Evaluation of investigations conducted to detect and prevent transmission of tuberculosis. JAMA 2002; 287: 991-995.
184 Lobato MN, Royce SE, Mohle-Boetani JC. Yield of source-case and contact investigations in identifying previously undiagnosed childhood tuberculosis. Int J Tuberc Lung Dis 2003; 7: Suppl. 3, S391-S396.

185 Espinal MA, Perez EN, Baez J, et al. Infectiousness of Mycobacterium tuberculosis in HIV-1-infected patients with tuberculosis: a prospective study. Lancet 2000; 355: 275-280.

186 Devadatta S, Dawson JJ, Fox W, et al. Attack rate of tuberculosis in a 5-year period among close family contacts of tuberculous patients under domiciliary treatment with isoniazid plus PAS or isoniazid alone. Bull World Health Organ 1970; 42: 337-351.

187 Cailleaux-Cezar M, de A Melo D, Xavier GM, et al. Tuberculosis incidence among contacts of active pulmonary tuberculosis. Int J Tuberc Lung Dis 2009; 13: 190-195.

188 Moran-Mendoza O, Marion SA, Elwood K, et al. Risk factors for developing tuberculosis: a 12-year follow-up of contacts of tuberculosis cases. Int J Tuberc Lung Dis 2010; 14: 1112-1119.

189 Diel R, Loddenkemper R, Meywald-Walter K, et al. Predictive value of a whole blood IFN-gamma assay for the development of active tuberculosis disease after recent infection with Mycobacterium tuberculosis. Am J Respir Crit Care Med 2008; 177 1164-1170.

190 Aspin J. Spread of adult-type pulmonary tuberculosis in contact households. Lancet 1952; 1: 502-507.

191 Lees AW, Allan GW, Smith J, et al. Pulmonary tuberculosis in contacts: a ten year survey. Dis Chest 1961; 40: 516-521.

192 Lee T, Kim N, Kim J. Diagnosis of latent tuberculosis infection by using the QuantiFERON-TB Gold in-tube test in children whose household contact has contagious pulmonary tuberculosis disease. Int J Infect Dis 2010; 14: e307.

193 Ponticiello A, Perna F, Sturkenboom MC, et al. Demographic risk factors and lymphocyte populations in patients with tuberculosis and their healthy contacts. Int J Tuberc Lung Dis 2001; 5: 1148-1155.

194 Akhtar S, Rathi SK. Multilevel modeling of household contextual determinants of tuberculin skin test positivity among contacts of infectious tuberculosis patients, Umerkot, Pakistan. Am J Trop Med Hyg 2009; 80: 351-358.

195 Petrucci R, Abu Amer N, Gurgel RQ, et al. Interferon $\gamma$, interferon-gamma-induced-protein 10, and tuberculin responses of children at high risk of tuberculosis infection. Pediatr Infect Dis J 2008; 27: 1073-1077.

196 Mutsvangwa J, Millington KA, Chaka K, et al. Identifying recent Mycobacterium tuberculosis transmission in the setting of high HIV and TB burden. Thorax 2010; 65: 315-320.

197 den Boon S, Verver S, Marais BJ, et al. Association between passive smoking and infection with Mycobacterium tuberculosis in children. Pediatrics 2007; 119: 734-739.

198 Shanaube K, Hargreaves J, Fielding $\mathrm{K}$, et al. Risk factors associated with positive quantiFERON-TB gold in-tube and tuberculin skin tests results in Zambia and South Africa. PLoS One 2011; 6: e18206.

199 Lewinsohn DA, Zalwango S, Stein CM, et al. Whole blood interferon- $\gamma$ responses to Mycobacterium tuberculosis antigens in young household contacts of persons with tuberculosis in Uganda. PLoS One 2008; 3: e3407.

200 Tornee S, Kaewkungwal J, Fungladda W, et al. Risk factors for tuberculosis infection among household contacts in Bangkok, Thailand. Southeast Asian J Trop Med Public Health 2004; 35: 375-383

201 Kifai EJ, Bakari M. Mantoux skin test reactivity among household contacts of HIV-infected and HIV un-infected patients with sputum smear positive TB in Dar es Salaam, Tanzania. East Afr J Public Health 2009; 6: 211-218. 
202 [Tuberculin skin testing of close contacts: recent or longstanding infection?]. Can Commun Dis Rep 2006; 32: 133-140.

203 Nakaoka H, Lawson L, Squire SB, et al. Risk for tuberculosis among children. Emerg Infect Dis 2006; 12: 1383-1388.

204 Rakotosamimanana N, Raharimanga V, Andriamandimby SF, et al. Variation in gamma interferon responses to different infecting strains of Mycobacterium tuberculosis in acid-fast bacillus smear-positive patients and household contacts in Antananarivo, Madagascar. Clin Vaccine Immunol 2010; 17: 1094-1103.

205 Narain R, Nair SS, Rao GR, et al. Distribution of tuberculous infection and disease among households in a rural community. Bull World Health Organ 1966; 34: 639-654.

206 Radhakrishna S, Frieden TR, Subramani R, et al. Additional risk of developing TB for household members with a TB case at home at intake: a 15-year study. Int J Tuberc Lung Dis 2007; 11: 282-288.

207 Ramakrishnan CV, Andrews RH, Devadatta S, et al. Prevalence and early attack rate of tuberculosis among close family contacts of tuberculous patients in South India under domiciliary treatment with isoniazid plus PAS or isoniazid alone. Bull World Health Organ 1961; 26: 361-407.

208 Lienhardt C, Fielding K, Sillah J, et al. Risk factors for tuberculosis infection in sub-Saharan Africa: a contact study in The Gambia. Am J Respir Crit Care Med 2003; 168: 448-455.

209 Lutong L, Bei Z. Association of prevalence of tuberculin reactions with closeness of contact among household contacts of new smear-positive pulmonary tuberculosis patients. Int $J$ Tuberc Lung Dis 2000; 4: 275-277.

210 Almeida LM, Barbieri MA, Da Paixao AC, et al. Use of purified protein derivative to assess the risk of infection in children in close contact with adults with tuberculosis in a population with high Calmette-Guerin bacillus coverage. Pediatr Infect Dis J 2001; 20: 1061-1065.

211 Raqib R, Kamal SM, Rahman MJ, et al. Use of antibodies in lymphocyte secretions for detection of subclinical tuberculosis infection in asymptomatic contacts. Clin Diagn Lab Immunol 2004; 11: $1022-1027$.

212 Hussain R, Talat N, Shahid F, et al. Biomarker changes associated with Tuberculin Skin Test (TST) conversion: a two-year longitudinal follow-up study in exposed household contacts. PLoS One 2009; 4: e7444.

213 Madico G, Gilman RH, Checkley W, et al. Community infection ratio as an indicator for tuberculosis control. Lancet 1995; 345: 416-419.

214 Aziz N, Hasan S, Munir M, et al. Risk to household contacts of tuberculous patients based on Mantoux test and antibody titre. J Ayub Med Coll Abbottabad 2008; 20: 47-50.

215 Hesseling AC, Mandalakas AM, Kirchner HL, et al. Highly discordant $\mathrm{T}$ cell responses in individuals with recent exposure to household tuberculosis. Thorax 2009; 64: 840-846.

216 Diel R, Loddenkemper R, Meywald-Walter K, et al. Comparative performance of tuberculin skin test, QuantiFERON-TB-Gold In Tube assay, and T-Spot.TB test in contact investigations for tuberculosis. Chest 2009; 135: 1010-1018.

217 Anibarro L, Trigo M, Villaverde C, et al. Tuberculin skin test and interferon-gamma release assay show better correlation after the tuberculin 'window period' in tuberculosis contacts. Scand J Infect Dis 2011; 43: 424-429.

218 Miller FJ. Work of a tuberculosis contact clinic for young children, 1941-5. BMJ 1947; 2: 91-94.

219 Johnson H, Lee B, Doherty E, et al. Tuberculin sensitivity and the BCG scar in tuberculosis contacts. Tuber Lung Dis 1995; 76: 122-125.

220 Ward LJ, Hughes SE, Grabau JC. The evaluation of schoolbased contact investigations in New York State, exclusive of
New York City, 1997-2001. J Public Health Manag Pract 2004; 10: 308-315.

221 Zaki MH, Lyons HA, Robins $\mathrm{AB}$, et al. Tuberculin sensitivity. Contacts of tuberculosis patients. NY State J Med 1976; 76: 2138-2143.

222 Conover C, Ridzon R, Valway S, et al. Outbreak of multidrugresistant tuberculosis at a methadone treatment program. Int $J$ Tuberc Lung Dis 2001; 5: 59-64.

223 Andre M, Ijaz K, Tillinghast JD, et al. Transmission network analysis to complement routine tuberculosis contact investigations. Am J Public Health 2007; 97: 470-477.

224 Cauthen GM, Dooley SW, Onorato IM, et al. Transmission of Mycobacterium tuberculosis from tuberculosis patients with HIV infection or AIDS. Am J Epidemiol 1996; 144: 69-77.

225 Cook VJ, Sun SJ, Tapia J, et al. Transmission network analysis in tuberculosis contact investigations. I Infect Dis 2007; 196: 1517-1527.

226 Centers for Disease Control and Prevention. Transmission of Mycobacterium tuberculosis associated with failed completion of treatment for latent tuberculosis infection - Chickasaw County, Mississippi, June 1999-March 2002. MMWR Morb Mortal Wkly Rep 2003; 52: 222-224

227 Centers for Disease Control and Prevention.: Cluster of tuberculosis cases among exotic dancers and their close contacts - Kansas, 1994-2000. MMWR Morb Mortal Wkly Rep 2001; 50: 291-293.

228 Johnsen C. Tuberculosis contact investigation: two years of experience in New York City correctional facilities. Am J Infect Control 1993; 21: 1-4.

229 Ames WR, Miles HC. Apparent decline in tuberculous infection among household associates of sputum-positive cases of tuberculosis. Am J Public Health Nations Health 1950; 40: 143-150.

230 Chapman JS, Dyerly MD. Social and other factors in intrafamilial transmission of tuberculosis. Am Rev Respir Dis 1964; 90: $48-60$.

231 Greenberg HB, Trachtman L, Thompson DH. Investigating the contacts and suspected contacts of tuberculous patients in New Orleans. South Med J 1977; 70: 829-830.

232 Asghar RJ, Patlan DE, Miner MC, et al. Limited utility of namebased tuberculosis contact investigations among persons using illicit drugs: results of an outbreak investigation. J Urban Health 2009; 86: 776-780.

233 LoBue PA, LeClair JJ, Moser KS. Contact investigation for cases of pulmonary Mycobacterium bovis. Int J Tuberc Lung Dis 2004; 8: 868-872.

234 Beyers N. Case finding in children in contact with adults in the house with TB. Int J Tuberc Lung Dis 2003; 7: 1013-1014.

235 Reichler MR, Reves R, Bur S, et al. Treatment of latent tuberculosis infection in contacts of new tuberculosis cases in the United States. South Med J 2002; 95: 414-420.

236 Begg CB, Mazumdar M. Operating characteristics of a rank correlation test for publication bias. Biometrics 1994; 50: 1088-1101.

237 Egger M, Davey Smith G, Schneider M, et al. Bias in metaanalysis detected by a simple, graphical test. BMJ 1997; 315: 629-634.

238 Kranzer K, Houben RM, Glynn JR, et al. Yield of HIV-associated tuberculosis during intensified case finding in resource-limited settings: a systematic review and meta-analysis. Lancet Infect Dis 2010; 10: 93-102.

239 World Health Organization Stop TB Partnership Childhood TB Subgroup. Chapter 4: childhood contact screening and management. Int J Tuberc Lung Dis 2007; 11: 12-15.

240 Veen J. Microepidemics of tuberculosis: the stone-in-the-pond principle. Tuber Lung Dis 1992; 73: 73-76. 
241 Erkens CG, Kamphorst M, Abubakar I, et al. Tuberculosis contact investigation in low prevalence countries: a European consensus. Eur Respir J 2010; 36: 925-949.

242 National Tuberculosis Controllers Association., Centers for Disease Control. Guidelines for the investigation of contacts of persons with infectious tuberculosis. Recommendations from the National Tuberculosis Controllers Association and CDC. MMWR Recomm Rep 2005; 54: 1-47.

243 Brown CA, Lilford RJ. The stepped wedge trial design: a systematic review. BMC Med Res Methodol 2006; 6: 54. 